Article

\title{
Feeling the Scope of Solidarity: The Role of Emotions for Volunteers Supporting Refugees in Germany
}

\author{
Serhat Karakayali \\ Faculty of Humanities and Social Sciences, Humboldt University Berlin, 10099 Berlin, Germany; \\ E-Mail: serhat.karakayali@hu-berlin.de
}

Submitted: 30 April 2017 | Accepted: 10 August 2017 | Published: 19 September 2017

\begin{abstract}
In recent political debates in Germany, volunteers and citizens who support the cause of refugees are often accused of being "too emotional". Based mainly on empirical evidence from 10 group discussions and 35 individual interviews with volunteers, conducted in 2016, this article undertakes a sociological analysis of the role of emotions for volunteers.
\end{abstract}

\section{Keywords}

emotion; Germany; refugees; solidarity; volunteers

\section{Issue}

This article is part of the issue "Perspectives on the European Border Regime: Mobilization, Contestation, and the Role of Civil Society", edited by Ove Sutter and Eva Youkhana (University of Bonn, Germany).

(C) 2017 by the author; licensee Cogitatio (Lisbon, Portugal). This article is licensed under a Creative Commons Attribution 4.0 International License (CC BY).

\section{Introduction}

This article explores the emergence of a movement of volunteers who work with asylum seekers in Germany. Based on quantitative and qualitative data, it intends to facilitate a better understanding of the role emotions play in volunteers' motivations (see also Sutter, 2017). In the sociological study of social movements, emotions have mostly been framed as being particular to the individual's intrinsic motivations for his or her participation in the respective movement, or as an element which contributes to a movement's collective dimension. Based on approaches that understand emotions as being closely linked to reason, this article aims to illustrate that emotions also operate at the boundaries of such collectives. As emotions express judgments and imply reasoning, they can reconfigure modes of belonging.

\section{Welcome Culture}

The public reaction towards the arrival of large numbers of refugees in Germany has been labeled a "culture of welcome/hospitality", a concept which had previously been associated with a reform of the labor market for highly-skilled migrant workers. ${ }^{1}$ However, during the summer of 2015 , the meaning of "welcome culture"

\footnotetext{
${ }^{1}$ The Dublin Regulation can be considered a form of Europeanization of the measures that were taken during the reform of the asylum-related paragraph in the German constitution in 1992. After its first "refugee crisis" in the 1990s, when around 400,000 Yugoslavian refugees arrived only in 1991, the parliament voted to add a paragraph to the constitution according to which asylum seekers could only apply for asylum when they had not crossed a safe country on their way to Germany. This reference to safe countries in the regulation is the principle by which main destination states in Europe have established a cordon sanitaire both within and outside the borders of the European Union. Politically, although Germany came to terms with its historical flows of immigration in around 2000, it still has no proper migration law. Entry requirements for potential migrants are designed in such a way that only highly qualified individuals, whose incomes are higher than average, are actually able to successfully immigrate. This is partly the result of a political impasse, to which trade unions also have contributed in their attempt to prevent a decline in average wages. This is the historical background of the term "welcome culture": The failure of immigration law to attract foreign labor and increasing concerns about demographics and a shrinking German population led to demand for a reform of the labor laws, predominantly by economists and employers' associations. Thus, the term "welcome culture" was largely introduced to the German debate by organizations such as the VDI (Verein deutscher Ingenieure; Association of German engineers) and the BDA (Bund Deutscher Arbeitgeber; Federation of German Employers). Strikingly, the term was often mentioned only in connection with the recruitment of specialists. In other words, the demand for a welcome culture seems to be a consequence of negative experiences with the so-called "green card" model and bureaucratic obstacles in Germany.
} 
changed for newly-arriving migrants. Beginning in August 2015 , hundreds of thousands of Germans joined voluntary associations or formed spontaneous initiatives in an effort to support the large numbers of refugees arriving in the country. Several surveys indicate that between 10 and 20 percent of Germany's adult population have joined such initiatives and projects aimed to help refugees since August 2015 (Ahrens, 2015; BertelsmannStiftung, 2017; SI EKD, 2016).

Trade unions, companies, public offices, and the media joined in a chorus of celebrating both the arrival of hundreds of thousands of refugees and asylum seekers, and of celebrating the hospitality offered by a significant portion of Germany's population. Even the populist and usually conservative-leaning tabloid BILD supported emergent grassroots hospitality with its own campaign, Wir helfen! (or "We Help!"). The events reported to the German public-refugees stranded in makeshift camps along the so-called Balkan route from Greece to Austria; trapped and beaten in a Budapest train station; the suffering of families and young children-and the positive response on the part of German authorities and the media helped to turn a pre-existent but small volunteer movement into a mainstream initiative, involving large and diverse parts of German society. At times, the engagement seemed to hyperbolize, particularly when Germans flocked to train stations in order to applaud arriving refugees, or when some drove their cars to Hungary or Croatia to bring refugees across the border to Germany or Austria (see Kasparek \& Speer, 2015; Misik, 2015). The atmosphere of these weeks was marked by excitement and enthusiasm, which, in turn, led to a political debate about the alleged irrationality of the all-too-positive feelings towards refugees on the part of the German public. For example, Phillip Lengsfeld, a member of parliament for the conservative CDU party, criticized BILD for covering the refugee crisis "too emotionally", and asserted that its attitude would "invite" refugees to come to Europe (Handelsblatt, 17.2.2016). The same topic was addressed in a strategy paper which dealt with civil resistance towards the deportation of newly-arrived refugees. The paper, produced by representatives of the German state's "Innenminister" (Ministry of Home Affairs), argued that "for a small, but active part of the population, as well as in large parts of the media, deportation measures and decisions are being portrayed exclusively from an emotional viewpoint, and not from the viewpoint of the rule of law (ordnungsrechtlich)" (quoted in Scherr, 2016 , p. 3). Authorities, politicians, and journalists expressed their concern about the role of emotions in pol- itics, based on the widespread notion that emotions are inherently irrational.

For most of the political and academic observers, the welcoming atmosphere during the first months of the so-called refugee crisis (Flüchtlingskrise) came as a surprise. One of the reasons people were astonished might be that public opinion about migration in Germany has been negative until quite recently. According to ALLBUS ${ }^{2}$ survey data from 1996, Germans wanted migration to be restricted $(57,1$ percent) or entirely banned $(34,8$ percent) for non-EU citizens. ${ }^{3}$ The data is similar regarding asylum seekers or so-called "resettlers" from Eastern Europe who possess a German background. Ten years later, in 2004, the share of Germans who stated that migration contributes positively to the economy was only around 27 percent; in the same year, almost 72 percent wanted less migration to Germany. These numbers changed significantly in the following decade: in 2014, roughly half of the respondents (51,4 percent) thought that migration has a positive impact on the economy and 49 percent wanted less immigration. These figures suggest that although public opinion regarding migration has shifted towards a more positive stance, the issue is still far from being uncontroversial (see GESIS 2014, 2015). This change in attitudes has also affected the public's view of asylum, despite the number of asylum seekers in Germany having reached a historical low in 2007 , when only 20,000 people applied-in fact, the lowest number in decades. From 2008 onwards, however, the number of applications started to rise again, almost exponentially. According to our own survey from 2014 (see below), the number of volunteers for refugees had increased between 2011 and 2014 by around 70 percent (Karakayali \& Kleist, 2015). Although the timeframes accounted for here do not entirely match, they still suggest that these two observations are related to each other.

\section{Database}

The findings presented here are based on four sets of data. The first two are online surveys: one of them conducted among volunteers and professionals working in support organizations. The first survey, conducted in 2014, involved 466 volunteers and 79 representatives from organizations in the field of refugee work; the second survey followed one year later, and included 2291 volunteers exclusively. Both were conducted online (Karakayali \& Kleist, 2015, 2016). ${ }^{4}$ The initial survey was planned and conducted at a time when there were apparently few people actively volunteering in this

\footnotetext{
${ }^{2}$ ALLBUS is a general social survey of the German population, conducted since 1980. It covers a wide range of item batteries, from socio-demographic to opinion data. ALLBUS is part of the International Social Survey Programme (ISSP), so findings are largely comparable to survey data in many other countries.

${ }^{3}$ As international social survey data suggests, these figures are not specific to Germany. The vast majority of respondents in the countries-from Australia to the Slovak Republic-participating in the International Social Survey Programme (ISSP Research Group, 1998) share similar attitudes towards immigration, i.e., between 60 and 80 percent of the respective populations are estimated to want immigration reduced. The only exceptions are Ireland-where only 21 percent of the respondents wanted less migration-and Spain, Canada and Japan with approximately 40 percent.

${ }^{4}$ The surveys were conducted together with Olaf Kleist (University of Osnabrück), the interviews were conducted in cooperation with Ulrike Hamann (Humboldt University) and our student assistants Mira Wallis, Leif Höfler and Laura Lambert.
} 
field. According to representative survey data on volunteering in Germany, the number of volunteers working with migrants or refugees as clients from 2009 was extremely small $(0,72$ percent of the sample in the FSW Study from 2009, Gensicke \& Geiss, 2010). The findings of this general survey imply that volunteering for migrantand/or refugee-related causes was, until very recently, a minor social phenomenon; these findings also explain why it was not possible to use existing databases on volunteering for the purpose of this study. The figures in the 2009 survey - the only database available until very recently-suggested that random sampling methods would require the collection of rather large samples. We therefore chose to address volunteering initiatives, associations, and organizations directly, by collecting approximately 1500 e-mail addresses throughout the country. The downside of this sampling strategy is that we could not control its representativity. However, the repetition of the survey with an almost unchanged questionnaire, sent to the same addresses, partly alleviated this downside. It allowed us to compare the two datasets diachronically, revealing certain developments over time. What is striking about the samples is the increase in the number of respondents from the first survey to the second survey. This is likely due to the significant number of people who became active in migrant- and refugeerelated work in 2015, rather than due to the use of a different sampling strategy. More than 60 percent of respondents in the second survey stated that they became active in 2015. The third set of data consists of semi-structured interviews with individuals who coordinate volunteer activities (mostly volunteers themselves) in thirty communities across Germany (dataset referred to as (O), which were led in February and March 2016. Another round of interviews was conducted with volunteers later that year, both as individual interviews and as group interviews held in different cities and "Bundesländer" (German states). For the analysis of emotions in the emergent volunteering movement, it is primarily these interviews which will be used.

\section{Emotions, Atmospheres and Social Movements}

The study of emotions had a comeback in Social Movement Studies, where it had led "a shadow existence for the last three decades" (Goodwin, Jasper, \& Polletta, 2000 , p. 65), i.e. since social movement scholars towards the end of the 1960s felt the need to balance the thenprevalent notion that social movements were merely the result of the irrational behavior of crowds and mobs. Crowds were assumed to be governed by almost hypnotic processes that "overwhelmed individual personalities and moved them beyond reason and normal sensibilities" (Goodwin et al., 2000, p. 66). Breaking with the pejorative tradition, scholars since the 1970 s looked for different theoretical models and mostly found them in approaches which emphasized the rationality of social and political agents: "The task for sociologists has been to show how these spontaneous and apparently unpremeditated outbreaks of disorder could still be defined as rational in terms of their underlying motivation" (Waddington, 2008, p. 6).

With the dominance of the mobilization model, researchers are now mostly interested in how protest is organized, framed and mobilized. What prominent scholars of Social Movements Studies such as James Jasper and others have criticized is that with this paradigm, emotions are kept entirely out of focus, although they apparently play an important role in protest-or, as Borch argues, they even led researchers to "misunderstand the causal mechanisms by which their own key concepts operated" (Borch, 2009, p. 71). As Benford has noted two decades ago, "we continue to write as though our movement actors (when we actually acknowledge humans in our texts) are Spock-like beings, devoid of passion and other human emotions" (Benford, 1997, p. 419) The main reason emotions needed to be kept out of the study of social movements was that the "new generation of theorists shared with the older ones one big assumption, namely, that emotions are irrational" (Goodwin et al., 2000, p. 71). There is a large body of literature dealing with the nature of emotions in the social sciences; the range of theories spans from hard and soft constructionist views, i.e. that emotions are social in nature or at least socially shaped (Boiger \& Mesquita, 2012; Hochschild, 1983), to approaches that consider feelings to be naturally "pre-wired" in the brain (e.g., Ekman, 1972; Izard, 1991). It seems that judgement about the irrationality of emotions is tied in with the latter, naturalistic idea, which also corresponds to the mind-body dualism which is characteristic of Western thought.

Of particular interest for the purpose of my argument is work which focuses on the role of emotions in the forging of social bonds and in the formation of collectives, such as the work of Thomas Scheff (1994), who, as did Goffman (1963) half a century earlier, has analyzed feelings of shame and pride as being constitutive for the formation of collective action. Scheff understands them to be essentially social, as they regulate the attachment of individuals to each other, where pride connects and shame disconnects. James Jasper (1998) adds to this, more generally, the affective ties of love, friendship, and-particularly important for the context of this article-solidarity as emotions that make collectives. Although feelings play a more prominent role now, they are still largely conceptualized within the mechanics of movements as organisms. Positive feelings have bonding functions for the respective "in-group", i.e. (potential) participants in a social movement or any given social collective. This line of thought corresponds with how sociologists since Durkheim have conceptualized the function of emotions for transindividual entities (families, groups, collectives, communities, nations, etc.). Randall Collins e.g. sees "emotional energy" as a key to understanding collectives, formed in face-to-face interactions and through "interaction ritual chains" (Collins, 2001). Soli- 
darity, both in the recent conceptualization of emotion in social movement studies, and in most of the general sociological literature (Bayertz, 1999), is seen as the bond between members of a given group or collective. Feelings can create and constitute, or in a weaker version, enhance and influence, these bonds, but there is rather little attention paid to how emotions contribute to expanding the group or remaking it with new parameters. If emotions are important for in-group relations, they should also be important for those phenomena where actions and relationships exceed the group or collective, or where the constitution of the groups is characterized by strategies of expansion, as Wimmer (2008) has called them. To put it the other way around: if solidarity signifies that a number of otherwise unconnected individuals have something in common, and feel that they belong together or should form a collective, then what can be said of "international solidarity" or, solidarity with foreigners, immigrants, or in our case, refugees? If being part of a society means that people who are strangers to each other come to engage with through a network of dependencies and complex mediated relationships, a study of solidarities with non-members of a given group or society might contribute to a more profound understanding of solidarity in general. To be able to do this, we have to emphasize that our understanding of emotions should not be confined to the subject's inner sphere and that we should try to capture what escapes, exceeds, or transcends this inner life of the subject towards what "affects" others (Hatfield, Cacioppo, \& Richard, 1994). This includes questions of how feelings circulate, how they are transmitted, and how this sometimes results in a change of the social or political "atmosphere". 5

\section{Emotions as Judgements}

There is solid evidence today that emotions are culturally shaped and that emotions as we know them would be unthinkable without social interaction. Emotions are linked to objects and reason, they are, e.g. structured by expectations, status, and hierarchy (Jasper, 2014). The emotions with which we react to a particular observation depend also on the process of attribution (or models of causation). We can only be angry or outraged if an- other subject (individual, collective, or juridical person) can be blamed, whereas we might feel shame if it turned out that we were responsible ourselves. The latter example also reveals how feelings impact us in different ways. Jasper associates indignation with activation ("can move us toward action"), and shame with passivity ("deflating", Jasper, 2014, p. 345). ${ }^{6}$ This is also why emotions are linked with judgments, or can at least be understood to convey judgments. Without necessarily having to go as far as Nussbaum and others (Nussbaum, 1996; Ortony, Clore, \& Collins, 1988), who equate emotions with cognition, they clearly are more than pre-cognitive entities opposed to reason, as the century-long debate about crowds has implied.

\section{Methodology}

What people feel and what they say is not always coherent. Compassion and sympathy towards refugees is explained or reasoned for by participants of this study in a variety of ways. Individuals usually feel the need to "justify" or to provide reasons for their actions; rarely did we encounter a participant who simply said she helped because she "felt that way". The more contentious an issue is, the more subjects are exposed to what Boltanski and Thévenot (2006) call a "justification imperative". While all kinds of social action are framed by their agents, advocating for immigration might demand more reasoning (see data about attitudes towards migration from ALLBUS survey, mentioned above). Volunteers usually outline certain conditions for their willingness to welcome migrants. These include the geographical extension of their solidarity as much as refugees' readiness to adapt to cultural and social norms in Germany. These preconditions structure, I argue, the modalities of feeling (can refugees be blamed for their own situation? Are they really in need of help?, etc.) and they simultaneously represent building blocks of different modes of belonging, or the lack thereof. Responding to the need to offer persuasive reasons, rather than simply reflecting on intrinsic motivation, social agents are compelled to engage-often publicly-with private notions of what is accepted and understood as common sense, as well as with contested and opposing visions articulated in

\footnotetext{
${ }^{5}$ The term 'atmosphere', used above in a rather colloquial way, can shed light on this problem: From a sociological point of view an atmosphere is a field of emergence, just as the metereological background of the metaphor implies. Rather describing a definite state of things (in terms of weather: rain, wind, temperature) it represents an impersonal intensity or environment (McCormack, 2008; Stewart, 2007) that "presses upon us" to think, act or feel in a certain direction, exerting a force on everyone who is surrounded by it. Just as the metereological ones, sociopolitical atmospheres result from the interplay of myriads of micro-level events, i.e. (inter-)actions on the social plane. The "atmosphere", in which people feel drawn to participate in welcoming activities for asylum seekers is both impersonal, and nothing any social or political agent intentionally created, and extremely meaningful on a personal level. As Ben Anderson has put it, they are "an ill-defined indefinite something, that exceeds rational explanation and clear figuration. Something that hesitates at the edge of the unsayable. Yet, at one and the same time, the affective qualities that are given to this something by those who feel it are remarkable for their singularity." (Anderson, 2009, p. 78) The concept of atmosphere allows us to reflect upon how the sum of singular encounters, actions, etc. emanate into a transpersonal sphere, and how then this "atmosphere" provides the ground for the space of emergence (of new things). Atmospheres thus "are a kind of indeterminate affective 'excess' through which intensive space-times can be created." (Anderson, 2009, p. 80). They can contribute to the re-arrangement of the patterns that regulate the relation between the individual and transindividual level, which together form political bodies or the "socius".

${ }^{6}$ This is one of the central arguments of affect theories deriving from Spinoza (1677/2000): Affects have either passivizing effects or they increase the subject's power to act. While there are numerous interpretations and nuances added to this central theme in contemporary affect theory, Spinoza essentially believed that "passions" and their deflating qualities can be neutralised by our appropriate understanding of their true causes, i.e. by reason.
} 
public. It is assumed that reason has a constitutively social quality: through reasoning, we make an implicit statement revealing our ideas regarding social relations and the ways in which human beings are connected to one another. For example, participants who reason that refugees are a welcome labor force rely on market-type social relations, implying a mode of connection which is rather utilitarian. Also, this kind of communication implies a certain strategic dimension (Snow \& Byrd, 2007; Westby, 2002). Social and political agents calculate the possible successes of framing strategies by considering hegemonic norms, potential connections, interventions, or dynamics. Thus, frames are particularistic by favoring one perspective over another, but their particularism needs to be expressed in more universal ways. To be convincing, social agents will choose reasons and arguments which allow others to share their view and to find the perspective "convincing", as formulated by the NeoGramscian school of political theory (Overbeek, 2000). This is why reasons provided by individuals and other social agents do not necessarily represent their intrinsic motivation or emotional setup. One of the difficulties that arises from this constellation has methodological consequences: How to identify emotions if what people express in narrations is mostly situated on the level of reason, social norms, and justifications?

As Kleres (2010) has pointed out even within a sociological framework, there is little methodological insight on how to conduct an analysis of narrative material with regard to its emotional dimension. He suggests reconstructing emotional dimensions and layers of emotional meaning through a narrative analysis, based on the seminal findings of Schütze (1983). Schütze's basic argument is that a principle homology exists between "ad hoc narratives and original processes of experience" (Kleres, 2010, p. 196). The narrative structure of any faceto-face communication, he argues along with Schütze, "forces the narrator to include the necessary and sufficient aspects in order to constitute a plausible, coherent, and complete story" (Kleres, 2010, p. 196). While only the narrative structures run parallel to the past experience, the argumentative patterns are "expressive of present contexts". As I argue, they also imply a certain pattern of coherence. The barriers or fissures between present context and past experience are transported by all kinds of linguistic expressions, ranging from symptomatic leaps to hyperboles. Basing the analysis on the narrative dimension allows for a reconstructing of the ways in which agency is emotionally loaded. One way of understanding emotions here is to look at the attribution of agency and the construction of relationships in the narratives, in which e.g. harm is done from one person to another. Can we blame someone else, or is there no "social address", as with natural disasters? This corresponds to Spinoza's theory of the affect in which agency is defined as a capacity to act (and not be acted upon), which is correlated to feelings of joy or sadness. In anger narratives we can trace how a subject narrates the "self as an object" (Kleres, 2010), and helplessness can be determined by identifying grammatical features such as modal auxiliaries, try predicates, and negation (Capps \& Ochs, 1995). We can see then how anger relates to the notion of a causal relationship, particularly when subjects do not become angry because "they found no one to ascribe agency to" (Kleres, 2010, p. 192). In his own empirical work, Kleres studied the relationship between types of emotional patterns and the scope of solidarity voiced by interviewees. Similar to his argument about the particular relationship between cognitive operations and feelings that result in different layers or scales of solidarity, I will in the following explore how emotions and reason interconnect in the narration of volunteers who help refugees in Germany.

\section{Scope and Scale of Solidarity}

One of the ways we tried to capture this problem was by discussing possible deportations of refugees following negative decisions about their asylum applications. In their study on deportation protests in Austria, Rosenberger and Winkler (2013) have outlined a typology of arguments used by those seeking to undermine deportation efforts. According to the authors, there are three different types of argumentation focusing, respectively, on concepts of integration, humanity, and human rights (Rosenberger \& Winkler, 2013, p. 124). While local groups mostly invoke the first principle, translocal groups also refer to the other two. Campaigns against deportations are mostly local and centered around an individual case, as Ruedin and Merhaut (2016) have shown in a longitudinal comparison of three countries (Germany, Switzerland, Austria). The social proximity between citizens and deportees seems to allow for stronger kinds of engagement. Such local campaigns are often capable of mobilizing citizens across the political spectrum, under the condition that the initiative is stripped of a noticeable political affiliation. Personal proximity can also lead to the development of emotional bonds, sometimes expressed in family metaphors, in which German volunteers describe refugees as "children". While such involvement can produce strong forms of engagement, it does not necessarily lead to a universalizing reasoning about migration, borders, and citizenship. By asking our participants about such real or potential deportations, we wanted to explore the two tendencies involved here. Would volunteers oppose such a decision (and also act upon their opposition), or were the relationships that volunteers had established with refugees "conditional" on the formal validation of their status as refugees? In this context, questions about the scope of volunteers' solidarity also emerged: When do volunteers feel they need to act-when migrants were stranded in Macedonia, or after they arrived in German neighborhoods? During the initial months, at the height of the socalled refugee crisis, as mentioned above, there were numerous reports about volunteers travelling to Slovenia, 
Croatia, and Greece to help the refugees on arrival and to try to facilitate their respective journeys to Germany. During group interviews, we discovered that volunteers employed a number of different approaches when discussing such topics. One of them was to frame responses on the micro-social level. Most of our informants began their involvement at the point in time when refugees arrived at local shelters or housing facilities, inevitably fusing local lives with those of the newly-arrived asylum seekers. Proximity and responsibility were connected, as one respondent underlined:

We could not deal with the images from Budapest anymore. You cannot watch these scenes, happening 300 kilometers away. It's hard to bear-at least for me and many others I know, too. That does not mean that everyone in the whole world should come to live in Germany, of course-but there is a concrete problem that requires a concrete and immediate solution.

In the same conversation, another participant said that relationships with refugees would have to remain nonetheless casual:

This might sound cruel, but we all have to move on to other places someday. I see it that way. So, if I meet you today, I might find you very pleasant, but I may well never see you again. Too bad. But I cannot pursue every possible friendship, because I already know enough people. However, if you need help now, or if I see you somewhere on a train and in need of assistance, I support you immediately.

In this sense, proximity and the bonds developed out of contact serve as a regulatory principle to organize decisions about when and to whom voluntary assistance is offered. This principle seems to apply to the emotional realm as well. Volunteers who emphasized that they tried to avoid emotional proximity often employed more utilitarian arguments to justify their involvement. For example, one participant explained that, in order to maintain a certain distance, she would never accept dinner invitations from refugees. Such a relationship also became the object of public debate at the height of the so-called refugee crisis in Germany, when the head of the Council of the Protestant Church in Germany, Heinrich BedfordStrohm, advocated for what he called an Abschiedskultur ("culture of farewell") as opposed to Willkommenskultur. The term was soon picked up by other politicians, who argued that it was necessary for Germans to prepare themselves for the fact that many asylum seekers would be denied protection either because they would not fulfill the criteria determined by the asylum law or because they had already applied for asylum elsewhere. These asylum seekers would have to return. The statement highlighted the role of emotions in decision-making about refugee politics as an eminent dimension in the public debate. However, the importance of personal bonds with refugees, and the correlation with political claims, appear to be more complex.

Almost all informants in the study conveyed that emotions played a role in their volunteering experience. Data from two surveys (Karakayali \& Kleist, 2016) suggests that, in particular, those volunteers who began helping refugees in 2015 assess their activities more often as emotionally important than did volunteers who were active before 2014. I want to highlight two cases here, which represent rather unusual accounts of narrating emotions, since they both emphasize their distance to emotionality. One informant in our study stood out for his self-depiction as sociopathic or non-social. His motivation to engage, and why he would not "fraternize" with refugees, was combined with descriptions of everyday avoidance strategies. His narrative starts with a story about his commute to work, which led him past a reception shelter for refugees; in the peak of the reception crisis, this shelter was crowded with refugees, many of whom had to sleep in front of the building. As seeing families lying on cardboard was "hard to bear" (VEG, Interview 3, p. 2) for him, he decided to change his route. Of course, he concedes, he could not entirely suppress the information, and he eventually had to engage. In another passage, this participant talks more generally about this strategy, i.e., that he tried to not let certain images and information affect him too much: "I try to not let that getting too close to me. I am not fading it out entirely, but I also try to not let it too near me" (VEG, Interview 3, p. 4). Volunteering for a good cause is something he portrayed as normal by referring to the environment in which he grew up as an "environment where you just help" (VEG, Interview 3, p. 5). Usage of the term "normal" or, more often, the phrase "helping is the most normal thing in the world" (VEG, Interview 3, p. 6), also in other cases, seems to help avoid talking about personal motivation and feelings. When it came to his feelings, he mostly seemed to recount how to avoid having them, thus implicitly conveying their impact.

This complexity can in part be attributed to the ways in which cognitive acts and emotions relate to each other. As mentioned above, one way to understand this relation is to look at the narrative structure of responses to the "deportation" question. This is a moment where most interviewees had trouble formulating a clear-cut answer. Usually, they had talked about their empathy towards the refugees that they worked with in earlier parts of the conversation. Being confronted with the possibility of deportation-which is not something entirely virtual but something that actually happens-their narrations slowed down, and the narrators stumbled. Interview 1 sets an example (VEG, Interview 1, p. 23), when the enumeration of the possible options the narrator would have is marked by indications of insecurity ("eh eh eh"). The tension between feelings and possible actions was highlighted in her statement "Or I, - I would certainly be affected....But I wouldn't know a solution". The overall pattern of the narration was oscillation, a 
back and forth between the feeling of urgency and her incapability or hesitation to translate this feeling of "being affected" into what she considered appropriate responses on the level of action. Her conclusion, "I have never done such a thing", suggests that she could not, or she might not have wanted, to elucidate reasons why she would have to subscribe to decisions of authorities concerning the residence of asylum seekers. She rather shifted her incapacity to act to a merely pragmatic argument. "I have never done such a thing," is something we say when we do not want to perform the respective action without genuinely ruling it out. It is important to mention that her feelings of sympathy towards refugees are entirely generic. She had no personal social relationship with any refugee. Her reticence regarding the issue of opposing deportation might thus be rooted in the fact that her position was grounded in moral considerations, not in personal bonds. This might also explain why her strongest depiction of feelings referred to volunteers or people who showed compassion, not refugees. In her description of donations from the population (VEG, Interview 1, p. 13), she used the word "overwhelming" three times in a row (the German term "umwerfend" is unusual here because it is used more commonly in aesthetic contexts, when something is considered extraordinarily beautiful). When asked whether she remembered intensive moments, the informant first answered negatively,

not with the refugees...

but I do find intense the reactions of the population ehm, when there is a k-call for donations, what kind of a reaction there was. I found that quite,... really stunning. Stunning."

Interviewer: Mmh.

Informant: Stunning.

The majority of volunteers reported similar experiences of excitement. One interviewee described it as a feeling of sociality: "I am really happy and this is, is a feeling like, being part of a whole" (VEG, Interview 8, p. 29). She also used terms such as "pride", "joy", and a "feeling of happiness" (VEG, Interview 8, p. 29). Another participant (VEG, Interview 14, p. 2) recollected how she mobilized her social environment, starting with her own family: "Then I called my father, whether he could help out, and our older daughter and then, I have to say, we were suddenly 35 people. Really, that was very moving, very diverse, old and young, men and women, East and West. It was awesome." Here, reason and emotion address the formation of in-group collectives. The feeling of being part of a larger community can be associated with problematic tendencies concerning the effects of mass psychology, but it also reveals, in a Spinozian perspective, the appropriate insight that the individual's capacity to act is indeed tied up with external, social conditions of action. From the perspective of social movement studies, this is an example of a type of emotion which has cohesive effects on the virtual collective of volunteers (love, friendship, pride). The subject, rather than being affected by its own actions, is "overwhelmed" - apparently in a positive way-by the compassionate actions of others (of which she saw herself as being part of).

Thus, there are two ways in which one of the most common metaphors for proximity-the family-comes into play: 1) Refugees are seen and addressed as family members, and volunteers often describe being enriched socially and culturally by the experience. This reflects a particular possibility towards integration or "becoming German"; and 2) Family terms are not used as a means to describe emerging emotional bonds between volunteers and refugees, but are rather intended to mobilize empathy and evoke the notion of equality: refugees are said to be "just like us", and their decision to migrate is thus comprehensible, since "we" would do so, too (often referring to family experience in the aftermath of World War II).

When a desire to help others is based on the experience of proximity and compassion, one might assume that volunteering would contribute to the reproduction of asymmetrical power relations. As Didier Fassin and many others have argued, if caregivers retain the power to decide who will receive what kind of help, this reproduces a "relation of inequality" (Fassin, 2012, p. 3). Our study explored this phenomenon by introducing the topic of gratitude. According to Boltanski's work on the mechanisms of charity, based on Adam Smith's theory of Moral Sentiments, one of the decisive elements of the relationship between benefactor and recipient is the latter's display of gratitude (Boltanski, 2004). In our interviews, we asked volunteers whether they were ever frustrated with their work, or if they felt exploited etc. In our fieldwork, and also in the group discussions, we often came across stories about volunteers, who e.g. were angry with refugees "cherry-picking" donated clothes or not showing up to German classes. When we brought up these issues during our conversations, the majority rejected the notion that they would want "something in return". Volunteers wanted to avoid the impression that they condition their commitment on reciprocity. After narrating experiences of disappointment, they usually emphasized their understanding and provided a variety of justifications or explanations for those incidents. Here, the reasons given by volunteers seemed to dampen their own negative feelings. The most common way to do this was to remove or replace responsibility from refugees to, e.g. the asylum system. What volunteers achieve with this operation is not confined to the regulation of internal emotional mechanisms, it also contributes to the reproduction of a consensus in the volunteer and refugee supporters' movement, according to which refugees have to be portrayed as victims, deprived of their agency (see Hess \& Karakayali, 2016). 
According to Fassin, this imbalance lies at the heart of humanitarianism: it does not necessarily result in the claim for fundamental rights. Immanuel Kant made the same argument in his Perpetual Peace, insisting that the protection of strangers is not a question of philanthropy, but of rights (see Kant, 1795/1983, Article 3). ${ }^{7}$ Philanthropy can be seen as a rather weak foundation, leaving the decision of whether or not an individual in need will receive assistance to entirely volatile factors. Most importantly, humanitarianism's tendency to exclude references to the social or political context of suffering plays a decisive role for such critiques (Whitebrook, 2002, p. 530). There are instances in which volunteers feel drawn to the experience of refugees as fellow human beings, leading to an identification of injustices that must be addressed. In other cases, however, volunteers seem to avoid the contextual themes that would bring questions of global inequality to the fore, and instead focus on issues of integration. The grievances in such accounts focus on the state authorities' lack of organization to provide resources for integration efforts.

\section{Conclusion}

The aim of this article was to better understand the relationship between emotions, reasoning, and the construction of social bonds (or of their expansion). The findings of the study show that some volunteers "manage" their emotions in order to avoid being affected, while others experience "happiness" as a result of their "capacity to act". Meanwhile, the emotional regime of charity, in which a certain hierarchy or imbalance is implied, seems to be in place. The scope of solidarity is rather narrow. There are only very few accounts of transnational social connectedness. Mostly, volunteers place their solidarity within a local or national framework. When volunteers reframe the cause of refugees as a local problem, a problem of local infrastructures, of the local hostility of other citizens etc., they tend to suppress other aspects, i.e., the political and social context of forced migration. The findings above suggest that volunteers, rather than expanding collectivities or redefining group membership, tend to engage in a way that allows them to maintain established boundaries of belonging. When it comes to the constitution of collectives, feelings of responsibility for refugees, in most cases, rather seem to help constitute the collective of volunteers-and respectively, the community or neighbourhood they live in.

\section{Acknowledgments}

The research for this article was financially supported by the Integration commissioner of the Federal government, the Hertie-Foundation and the BertelsmannFoundation. Thanks go to Mira Wallis, Leif Löffler, Mareike Heller and Laura Lambert for their assistance in data collection and to Ulrike Hamann and Olaf Kleist for productive collaborations in the different research projects that helped generate the data used in this article.

\section{Conflict of Interests}

The author declares no conflict of interests.

\section{References}

Ahrens, P. (2015). Skepsis oder Zuversicht? Erwartungen der Bevölkerung zur Aufnahme von Flüchtlingen in Deutschland. Hannover: EKD. Retrieved from www.ekd.de

Anderson, B. (2009). Affective atmospheres. Emotion, Space and Society, 2(2), 77-81.

Bayertz, K. (1999). Solidarity. Dordrecht: Kluwer Academic Publishers.

Benford, R. D. (1997). An insider's critique of the social movement framing perspective. Sociological Inquiry, 67(4), 409-430.

Bertelsmann-Stiftung. (2017). Engagement für Geflüchtete-Eine Sache des Glaubens? Die Rolle der Religion für die Flüchtlingshilfe. Berlin: BertelsmannStiftung.

Boiger, M., \& Mesquita, B. (2012). The construction of emotion in interactions, relationships, and cultures. Emotion Review, 4(3), 221-229.

Boltanski, L. (2004). Distant suffering: Morality, media, and politics. Cambridge: Cambridge University Press.

Boltanski, L., \& Thévenot, L. (2006). On justification: Economies of worth. Princeton: Princeton University Press.

Borch, C. (2009). Body to body: On the political anatomy of crowds. Sociological Theory, 27, 271-290.

Capps, L., \& Ochs, E. (1995). Out of place: Narrative insights into agoraphobia. Discourse Processes, 19, 407-439.

Collins, R. (2001). Social movements and the focus of emotional attention. In J. Goodwin, J. Jasper, \& F. Poletta (Eds.), Passionate politics: Emotions and social movements (pp. 27-449). Chicago: University of Chicago Press.

Ekman, P. (1972). Universals and cultural differences in facial expressions of emotion. In J. Cole (Ed.), Nebraska Symposium on Motivation, 1971 (pp. 207283). Lincoln, NE: University of Nebraska Press.

Fassin, D. (2012). Humanitarian reason: A moral history of the present. Berkeley: University of California Press.

Gensicke, T., \& Geiss, S. (2010). Hauptbericht des Freiwilligensurveys 2009. Ergebnisse der repräsentativen Trenderhebung zu Ehrenamt, Freiwilligenarbeit und Bürgerschaftlichem Engagement. Berlin: Bundesministerium für Familie, Senioren, Frauen und Jugend.

\footnotetext{
7 "Es ist hier, wie in den vorigen Artikeln, nicht von Philanthrophie, sondern vom Recht die Rede, und da bedeutet Hospitalität (Wirthbarkeit) das Recht eines Fremdlings, seiner Ankunft auf dem Boden eines andern wegen, von diesem nicht feindselig behandelt zu werden." (Kant, 1795/1983, Article 3)
} 
GESIS. (2014). Allgemeine Bevölkerungsumfrage der Sozialwissenschaften ALLBUS 1996 (ZA2800 Datenfile Version 2.0.0.). Cologne: GESIS Datenarchiv.

GESIS. (2015). ALLBUS/GGSS 2014. (ZA5240 Data file Version 2.1.0.). Cologne: GESIS Data Archive.

Goffman, E. (1963). Stigma. London: Penguin.

Goodwin, J., Jasper, J., \& Polletta, F. (2000). The return of the repressed: The fall and rise of emotions in social movement theory. Mobilization: An International Quarterly, 5(1), 65-83.

Hatfield, E., Cacioppo, J. T., \& Richard, L. (1994). Emotional contagion. New York: Cambridge University Press.

Hess, S., \& Karakayali, S. (2016). Fluchtlinien der Migration. Grenzen als soziale Verhältnisse. In S. Hess, B. Kasparek, S. Kron, M. Rodatz, M. Schwertl, \& S. Sontowski (Eds.), Der lange Sommer der Migration (pp. 25-37). Hamburg: Assoziation A.

Hochschild, A. R. (1983). The managed heart: Commercialization of human feeling. Berkeley: University of California Press.

ISSP Research Group. (1998). International social survey programme: National identity I - ISSP 1995 (ZA2880 Datenfile Version 1.0.0). Köln: GESIS Datenarchiv.

Izard, C. E. (1991). The psychology of emotions. New York: Plenum Press.

Jasper, J. (1998). The emotions of protest: Affective and reactive emotions in and around social movements. Sociological Forum, 13(3), 397-424.

Jasper, J. (2014). Emotions, sociology, and protest. In C. Scheve, \& M. Salmela (Eds.), Collective emotions (pp. 341-355). Oxford: Oxford University Press.

Kant, I. (1983). Perpetual peace, and other essays on politics, history, and morals. Indianapolis: Hackett Pub. Co. (Original work published 1795)

Karakayali, S., \& Kleist, O. (2015). Strukturen und Motive der ehrenamtlichen Flüchtlingsarbeit in Deutschland, Berlin: BIM. Retrieved from https://www.bim.huberlin.de/media/2015-05-16_EFA-Forschungsbericht _Endfassung.pdf

Karakayali, S., \& Kleist, O. (2016). Strukturen und Motive der ehrenamtlichen Flüchtlingsarbeit in Deutschland 2. Berlin: BIM. Retrieved from https://www. bim.hu-berlin.de/de/publikationen/2016/strukturenund-motive-der-ehrenamtlichen-fluechtlingsarbeitefa-in-deutschland-2

Kasparek, B., \& Speer, M. (2015). Of Hope. Ungarn und der lange Sommer der Migration. Bordermonitoring. Retrieved from http://bordermonitoring.eu/ ungarn/2015/09/of-hope

Kleres, J. (2010). Emotions and narrative analysis: A methodological approach. Journal for the Theory of Social Behaviour, 41(2), 182-202.

McCormack, D. (2008). Engineering affective atmospheres: On the moving geographies of the 1897 Andree expedition. Cultural Geographies, 15(4), 413-430.
Misik, R. (2015). Der Aufstand der 'freiwilligen Helfer'. Warum die Flüchtlingshilfe keineswegs nur 'karitativ' ist. Prager Frühling. Retrieved from https://www. prager-fruehling-magazin.de/de/article/1243.der-auf stand-der-freiwilligen-helfer.html

Nussbaum, M. (1996). Compassion: The basic social emotion. Social Philosophy and Policy, 13(1), 27-58.

Ortony, A., Clore, G. L., \& Collins, A. (1988). The cognitive structure of emotions. Cambridge: Cambridge University Press.

Overbeek, H. (2000). Transnational historical materialism in global political economy: Contemporary theories. New York: Routledge.

Rosenberger, S., \& Winkler, J. (2013). Anti-Abschiebungsproteste: Mit Empathie gegen die Exklusion. In I. Ataç, \& S. Rosenberger (Eds.), Politik der Inklusion und ExkIusion (pp. 111-134). Göttingen: V\&R Unipress.

Ruedin, D., \& Merhaut, N. (2016). Anti-deportation protest in Austria, Germany, and Switzerland. Paper presented at the 3rd ISA Forum of Sociology, Vienna, Austria.

Scheff, T. J. (1994). Bloody revenge: Emotions, nationalism, and war. Boulder: Westview Press.

Scherr, A. (2016). Vier Formen der Abkühlung moralischer Empörung. Ein Betrag zur Analyse politischer Reaktionen auf zivilgesellschaftliche Proteste in der Krise des Flüchtlingsschutzes. Paper presented at the 38th Congress of "Deutsche Gesellschaft für Soziologie", Bamberg, Germany.

Schütze, F. (1983). Biographieforschung und narratives Interview. Neue Praxis, 13(3), 283-293.

SI EKD. (2016). Skepsis oder Zuversicht? Erwartungen der Bevölkerung zur Aufnahme von Flüchtlingen zwischen November 2015 und August 2016. Hannover. Retrieved from http://www.ekd.de/fluecht lingsstudie2016.pdf

Snow, D. A., \& Byrd, W. (2007). Ideology, framing processes, and Islamic terrorist movements. Mobilization: An International Journal, 12(2), 119-136.

Spinoza, B. (2000). Ethics. Oxford: Oxford University Press. (Original work published 1677)

Stewart, K. (2007). Ordinary affects. Durham: Duke University Press.

Sutter, O. (2017). 'Welcome!' Emotional politics and civic engagements for refugees. Zeitschrift für Volkskunde, 113(1), 3-23.

Waddington, D. (2008). The Madness of the mob? Explaining the 'irrationality' and destructiveness of crowd violence. Sociological Compass, 2(2), 1-13.

Westby, D. L. (2002). Strategic imperative, ideology, and frame. Mobilization, 7(3), 287-304.

Whitebrook, M. (2002). Compassion as a political virtue. Political Studies, 50(3), 529-544.

Wimmer, A. (2008). Elementary strategies of ethnic boundary making. Ethnic and Racial Studies, 31(6), 1025-1055. 


\section{About the Author}

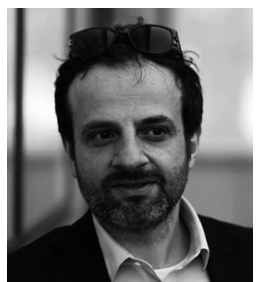

Serhat Karakayali $(\mathrm{PhD})$ is a sociologist and works as a researcher at the Berlin Institute for Integration and Migration Research (BIM) at Humboldt University of Berlin. In the last few years his research focused on volunteering for migrants and refugees in Germany and Europe, migrant advocacy and cosmopolitan concepts of solidarity. He is currently leading two research projects on the transformative impact of migration on civil society organisations and trade unions in Germany. He is one of the founding members of the research group "Transit Migration" and the "Research Network Critical Migration Studies". 